\title{
Consumer preferences for mass customization
}

Citation for published version (APA):

Dellaert, B. G. C., \& Stremersch, S. (2004). Consumer preferences for mass customization. METEOR, Maastricht University School of Business and Economics. METEOR Research Memorandum No. 042 https://doi.org/10.26481/umamet.2004042

Document status and date:

Published: 01/01/2004

DOI:

10.26481/umamet.2004042

Document Version:

Publisher's PDF, also known as Version of record

\section{Please check the document version of this publication:}

- A submitted manuscript is the version of the article upon submission and before peer-review. There can be important differences between the submitted version and the official published version of record.

People interested in the research are advised to contact the author for the final version of the publication, or visit the DOI to the publisher's website.

- The final author version and the galley proof are versions of the publication after peer review.

- The final published version features the final layout of the paper including the volume, issue and page numbers.

Link to publication

\footnotetext{
General rights rights.

- You may freely distribute the URL identifying the publication in the public portal. please follow below link for the End User Agreement:

www.umlib.nl/taverne-license

Take down policy

If you believe that this document breaches copyright please contact us at:

repository@maastrichtuniversity.nl

providing details and we will investigate your claim.
}

Copyright and moral rights for the publications made accessible in the public portal are retained by the authors and/or other copyright owners and it is a condition of accessing publications that users recognise and abide by the legal requirements associated with these

- Users may download and print one copy of any publication from the public portal for the purpose of private study or research.

- You may not further distribute the material or use it for any profit-making activity or commercial gain

If the publication is distributed under the terms of Article $25 \mathrm{fa}$ of the Dutch Copyright Act, indicated by the "Taverne" license above, 


\title{
Consumer Preferences for Mass Customization
}

\author{
Benedict G.C. Dellaert ${ }^{1}$ and Stefan Stremersch ${ }^{2}$
}

September 2004

\footnotetext{
${ }^{1}$ Professor of Marketing and Meteor Research Chair, Department of Marketing, Faculty of Economics and Business Administration, PO Box 616, 6200 MD Maastricht, The Netherlands, phone: +31 43388 3250, fax: +31 43388 4918, email:

b.dellaert@mw.unimaas.nl

${ }^{2}$ Professor of Marketing, School of Economics, Erasmus University Rotterdam, Burg. Oudlaan 50, 3062 PA Rotterdam, The Netherlands; phone: +31 10408 8719, fax: +31 10408 9160, email: stremersch@few.eur.nl.

Visiting Associate Professor of Marketing, Goizueta Business School, Emory University, USA, email: Stefan_Stremersch@bus.emory.edu
}

The authors gratefully acknowledge the financial support of the Marketing Science Institute (grant\#: 4-1117) and the Faculty of Economics and Business Administration at Tilburg University (The Netherlands) for data collection with the CentERdata panel. They also value the research assistance by Vladislav Golounov,as well as helpful comments by Pratibha Dabholkar, Bas Donkers, Gerald Häubl, Deborah MacInnis, Siddarth Sivaramakrishnan and Arthur van Soest. 


\title{
Consumer Preferences for Mass Customization
}

\author{
Abstract \\ Increasingly, firms adopt mass customization, which allows consumers to customize \\ products by self-selecting their most preferred composition of the product for a predefined set \\ of modules. For example, PC vendors such as Dell allow customers to customize their PC by \\ choosing the type of processor, memory size, monitor, etc. However, how such firms \\ configure the mass customization process determines the utility a consumer may obtain or the \\ complexity a consumer may face in the mass customization task. \\ Mass customization configurations may differ in four important ways - we take the \\ example of the personal computer industry. First, a firm may offer few or many product \\ modules that can be mass customized (e.g., only allow consumers to customize memory and \\ processor of a PC or allow consumers to customize any module of the PC) and few or many \\ levels among which to choose per mass customizable module (e.g., for mass customization of \\ the processor, only two or many more processing speeds are available). Second, a firm may \\ offer the consumer a choice only between very similar module levels (e.g., a 17” or 18” \\ screen) or between very different module levels (e.g., a 15” or 21 ” screen). Third, a firm may \\ individually price the modules within a mass customization configuration (e.g., showing the \\ price of the different processors the consumer may choose from) along with pricing the total \\ product, or the firm may show only the total product price (e.g., the price of the different \\ processors is not shown, but only the computer's total price is shown). Fourth, the firm may \\ show a default version (e.g., for the processor, the configuration contains a pre-selected \\ processing speed, which may be a high-end or low-end processor), which consumers may \\ then customize, or the firm may not show a default version and let consumers start from \\ scratch in composing the product.
}


The authors find that the choices that firms make in configuring the mass customization process affect the product utility consumers can achieve in mass customization. The reason is that the mass customization configuration affects how closely the consumer may approach his or her ideal product by mass customizing. Mass customization configurations also affect consumers' perception of the complexity of mass customization as they affect how many cognitive steps a consumer needs to make in the decision process. Both product utility and complexity in the end determine the utility consumers derive from using a certain mass customization configuration, which in turn will determine main outcome variables for marketers, such as total product sales, satisfaction with the product and the firm, referral behavior and loyalty.

The study offers good news for those who wish to provide many mass customization options to consumers, because we find that within the rather large range of modules and module levels we manipulated in this study, consumers did not perceive significant increases in complexity, while they were indeed able to achieve higher product utility. Second, our results imply that firms when increasing the number of module levels, should typically offer consumers more additional options in the most popular range of a module and less additional options at the extremes. Third, pricing should preferably be presented only at the total product level, rather than at the module and product level. We find that this approach reduces complexity and increases product utility. Fourth, firms should offer a default version that consumers can use as a starting point for mass customization, as doing so minimizes the complexity to consumers. The best default version to start out with is a base default version because this type of default version allows the consumer to most closely approach his or her ideal product. The reason is that consumers when presented with an advanced default may buy a product that is more advanced than they actually need. 
We also found that expert consumers are ideal targets for mass customization offerings. Expert consumers experience lower complexity in mass customization and complexity has a less negative influence on product utility obtained in the mass customization process, all compared to novice consumers. In general, reducing complexity in the mass customization configuration is a promising strategy for firms as it not only increases the utility of the entire process for consumers, but also allows them to compose products that more closely fit their ideal product. 


\section{Introduction}

The combination of advanced engineering and information technology allows firms to be highly flexible and responsive in providing product variety through mass customization (e.g., Pine, Victor and Boyton 1993) ${ }^{1}$. Marketing researchers however, are just beginning to explore the effectiveness of mass customization strategies from a customer's perspective (Huffman and Kahn 1998; Wind and Rangaswamy 2001). Liechty, Ramaswamy and Cohen (2001) modeled the product choices consumers make in a mass customization configuration.

Our research focuses on consumer preferences for different mass customization configurations. Mass customization configurations refer to the outline or arrangement of the different product modules that can be mass customized. For instance, mass customization configurations may differ in the number or levels of product modules that the consumer may customize, or in terms of the way in which total product and module level prices are presented to consumers. Little is known about how different mass customization configurations differentially affect the utility a consumer derives from mass customization.

The theory we develop to explain consumers’ preferences for mass customization configurations builds on choice task complexity theory (e.g., Bettman, Johnson and Payne 1990; Johnson and Payne 1985), consumer choice theory (McFadden 1986) and loss aversion theory (Tversky and Kahneman 1991). Its central premise is that consumers' latent utility for using a certain mass customization configuration (“mass customization utility”) is simultaneously

\footnotetext{
${ }^{1}$ In this study, we define mass customization as the type of customization in which an individual consumer's product preferences are met by choosing among predefined levels for each of a set of product modules. Product modules in this context are divisible components that jointly with other components make up a total product. The modules and levels that are included in the mass customization process are predefined by the firm, and we analyze the case in which consumers 'mass customize' the product by selecting their most preferred level for each product module. For example, PC vendors such as Dell allow customers to mass customize their PC by choosing a level for each of the different PC modules, such as type of processor, memory size, monitor, etc.
} 
affected by (1) the product utility that can be achieved by using the mass customization configuration ("product utility"), and (2) consumers' perception of the complexity of composing their product when using the mass customization configuration (“complexity"). It also identifies mass customization configuration factors that may differentially affect both product utility and complexity. To test the developed theory, we use data from an experiment of mass customized PC purchases. The extended logit model (Ashok, Dillon and Yuan 2002) that we specify simultaneously estimates: (1) the measurement equations for the latent constructs: product utility, complexity, and mass customization utility, (2) the effects of product utility and complexity on mass customization utility, and (3) the effects of mass customization configuration factors on product utility and complexity. It also allows for differences between consumers based on consumer expertise (e.g., Alba and Hutchinson 1987) and unobserved factors (through a random coefficient specification).

This paper contributes to the marketing literature in several ways. First, our focal question - why do consumers prefer one mass customization configuration over another - is novel and relevant. For instance, this question is relevant for companies such as Dell or HP to develop and adjust their mass customization configuration. Second, we develop a structural model that details which factors determine the utility a consumer derives from a mass customization configuration. Third, we find empirical support for the developed theory through estimating a random coefficient specification of the extended logit model.

\section{Research hypotheses}

In this section, we first theorize that two latent factors determine the utility a consumer derives from a mass customization configuration, namely product utility and complexity (see 
Figure 1). Second, we discuss the effect of mass customization configuration factors on product utility and complexity.

\section{The effect of product utility and complexity on mass customization utility}

First, we expect that mass customization configurations that allow consumers to select products of higher utility are evaluated more positively and therefore have higher mass customization utility. Second, we expect that more complex mass customization configurations are evaluated more negatively and therefore have lower mass customization utility. The reason is that increased complexity requires greater consumer effort to generate the same mass customized product (Johnson and Payne 1985), and that, all else equal, consumers like to minimize decision effort (Wright 1975).

H1a: The product utility that can be achieved by using a mass customization configuration has a positive effect on mass customization utility.

H1b: The complexity of using a mass customization configuration has a negative effect on mass customization utility.

We also expect that complexity may directly affect product utility. As mass

customization becomes more complex, it becomes more likely that consumers have to resort to simplifying decision heuristics (e.g., Newell and Simon 1972). The use of heuristics in turn makes it less likely that consumers select the product with the highest possible product utility. The reason is that heuristics force consumers to take into account only a subset of all module trade-offs and therefore the product they compose may be suboptimal.

H2: The complexity of using a mass customization configuration has a negative effect on the product utility that can be achieved by using a mass customization configuration.

\section{The effect of mass customization configuration factors on product utility and complexity}

We discern four factors on which mass customization configurations may differ and that may have differential effects on the product utility obtained through and the complexity of using 
a mass customization configuration. The first factor is the extent of mass customization. A configuration low in extent of mass customization may offer fewer modules that can be mass customized (e.g., only memory and processor of a PC can be mass customized) or fewer levels among which to choose per mass customizable module (e.g., for mass customization of the processor, only two processing speeds are available), than a configuration high in extent of mass customization.

The second factor is the heterogeneity in the levels available for a mass customizable module. A configuration low in level heterogeneity may offer only very similar module levels among which a consumer may choose (e.g., a 17” or 18” screen), while a configuration high in level heterogeneity may offer very different module levels among which a consumer may choose (e.g., a 15 ” or 21 ” screen). The third factor is the individual pricing of modules within a mass customization configuration. Modules may be individually priced (e.g., the price of the different processors is shown) along with showing the total product price or only the total product price is shown (e.g., the price of the different processors is not shown, but only the computer's total price is shown). The fourth factor is the presence and level of a default version. A mass customization configuration may show a default version (e.g., for the processor, the configuration contains a pre-selected processing speed) or it may not, and when a default version is shown, this may be a high-end (e.g., the highest processing speed is pre-selected) or low-end (e.g., the lowest processing speed is pre-selected) default version.

We identified these four mass customization configuration factors for two main reasons. First, when we examined existing mass customization configurations in the context of PC purchasing, we found differences between mass customization configurations were strongly pronounced on these four factors. Second, these four factors have a consistent theoretical 
background. They all affect complexity through the number of tradeoffs consumers need to make while composing their mass customized product. And, they all affect product utility through the extent to which consumers are able to select a product close to their ideal product (i.e., the product that has the most attractive combination of product components for that consumer). Extent of mass customization

Increases in the extent of mass customization lead to a greater number of possible products that can be composed through the mass customization configuration. On the one hand, such increases likely reduce the average distance between the mass customized product a consumer may compose and his/her ideal product, thereby increasing product utility. On the other hand, consumers need to tradeoff a greater number of possible product components. This, in turn, increases the number of cognitive steps in the consumer decision-making process, which increases perceived complexity (Bettman, Johnson and Payne 1990).

H3a: The extent to which products can be mass customized increases the product utility that can be achieved by using a mass customization configuration.

H3b: The extent to which products can be mass customized increases the complexity of using a mass customization configuration.

Level heterogeneity

An important determinant of product utility may be whether or not consumers can find their most preferred level, which is consistent with research on consumer perceptions of retail assortments (Broniarczyk, Hoyer and McAlister 1998). Given a certain extent of mass customization, a mass customization configuration that offers module levels that are relatively close to the mean (low level heterogeneity) allows a larger number of consumers to select their most preferred module levels, than a configuration with levels that are more dispersed (high level 
heterogeneity). Thus, we hypothesize that increasing level heterogeneity (for a given extent of mass customization) has a negative effect on product utility.

H4a: Increasing heterogeneity in module levels decreases the product utility that can be achieved by using a mass customization configuration.

Note that this hypothesis assumes that consumer module-level preferences are heterogeneous and concentrated around the mean (for example, following a normal distribution (Allenby, Arora and Ginter 1999)).

We also expect that greater level heterogeneity increases complexity. The reason is that we expect that decision complexity increases as the differences in the tradeoffs between different module levels increase. While Bettman, Johnson and Payne (1990) highlighted the effect of the number of cognitive steps on consumer decision complexity, others have shown that larger variance in trade-offs also increases choice complexity (Chatterjee and Heath 1996). As module levels become more heterogeneous, trade-off variance increases, and hence we expect complexity to increase as well.

H4b: Increasing heterogeneity in module levels increases the complexity of using a mass customization configuration.

\section{Individual pricing of modules}

Individual pricing of modules may affect product utility for several reasons. In particular, we expect that including individual pricing of modules makes price more salient to consumers since it more clearly expresses the prices associated with each module, and consumers tend to focus on information that is explicitly displayed (e.g., Slovic 1972). Individual pricing may also lead to a more disaggregate perception of monetary losses and hence a higher perceived total price (e.g., Tversky and Kahneman 1991). Therefore, we expect that individual pricing leads consumers to select less expensive product components, thereby obtaining a lower quality product when higher quality product components have higher prices. 
H5a: Individual pricing of modules decreases the product utility that is achieved when using a mass customization configuration.

We also expect that individual pricing of modules increases complexity because of the greater cognitive effort involved in processing the separate price information. Presenting individual module prices along with the total price emphasizes more clearly the separate costbenefit trade-offs that consumers need to make for each module. Therefore, we expect that on average consumers are likely to be more aware of the number of trade-offs (i.e., cognitive steps) they need to make and that this in turn leads to a greater perceived effort in the decision and a higher perceived complexity (c.f. Bettman, Johnson and Payne 1990; Johnson and Payne 1985).

H5b: Individual pricing of modules increases the complexity of using a mass customization configuration.

\section{Default version}

A final mass customization configuration factor that we address is the default version of the mass customizable product that is offered if any. Prior research suggests that across many different applications, consumers are more willing to switch 'up' to higher price, higher quality products, than to switch 'down' to lower price, lower quality products (e.g., Simonson, Kramer and Young 2003). A possible explanation for this effect is that there is an asymmetry in price and quality loss aversion that makes the quality loss relatively harder to compensate in monetary terms than vice versa (Park, Jun and MacInnis 2000; Tversky and Kahneman 1991). Based on these previous findings, we expect that, in case a base default is offered, consumers will select a product that is closer to their ideal product, than consumers that are presented with an advanced default, as the former will be more willing to switch up than the latter will be to switch down. H6: Offering a base default version leads to a higher product utility when using a mass customization configuration than offering an advanced default version. 
We also expect that providing a default version may affect complexity. The reason is that a default version that is closer to a consumer's ideal product may allow him or her to go through a smaller number of module-level comparisons than a default that is further away from the consumer's ideal product. Thus, depending on a consumer's preference, a base default version or an advanced default version may be closer to his or her product preference and complexity may be greater or smaller. We include a control variable in our model to allow for this effect.

\section{The role of consumer expertise}

Prior research has shown that consumer expertise plays a central role in consumers’ ability to deal with task complexity (e.g., Alba and Hutchinson 1987; Spence and Brucks 1997). Therefore, we expect that consumers with high consumer expertise experience less complexity when participating in mass customization than consumers with low consumer expertise (c.f. Huffman and Kahn 1998).

H7: Consumer expertise decreases the complexity of using a mass customization configuration. Furthermore, we expect that even if they perceive a certain mass customization configuration to be complex, consumers with high expertise are relatively less likely to have to resort to the use of decision heuristics and the heuristics they use will be more effective (c.f. H2). For example, Alba and Hutchinson (1987) argued that higher consumer expertise leads to a greater ability to analyze information and to select that information which is most important and task relevant. Therefore, we expect that the product utility that experts can achieve in mass customization is affected less strongly by complexity than that of non-experts ${ }^{2}$.

H8: The negative effect of complexity on product utility in using a mass customization configuration is weaker for consumers with high expertise than for consumers with low expertise.

\footnotetext{
${ }^{2}$ In our analysis we also control for the direct effect of consumer expertise on product utility.
} 


\section{Data}

We test our hypotheses through an experiment in which we manipulated mass customization configurations for PCs. We asked consumers to mass customize PCs under different experimental conditions that mimicked real-world mass customization configurations and to choose whether or not they would use the mass customization configuration if it were to become available. Thus, we could study consumers' choices whether or not to use a mass customization configuration depending on the factors that we hypothesized on (H3-H6) and manipulated in the experiment.

\section{Respondents}

Respondents in the experiment were real-life consumers that are members of an ongoing consumer panel of approximately 2,000 individuals at Tilburg University. Data were collected in 2001. The panel is Internet-based and is used to collect a variety of data. Respondents participated in the experiment in their own home using an Internet connection. Participants in the panel are selected randomly from the total population of the Netherlands and are provided with Internet access by the panel management if they don't have access at the time of becoming a member of the panel. After eliminating respondents under 16 years of age, respondents with no experience nor interest in PC purchasing, and respondents with missing values or invalid responses, 409 respondents remained. These respondents all had indicated that they either had an interest in purchasing a PC in the next two years, or had done so in the past four years. The average age of the respondents was 43.7 years old, 37.2 percent of the respondents was female and 52.6 percent held a bachelors degree or higher. Thus, the sample was somewhat biased towards older males with a relatively higher education. However, this may be typical for PC purchase decision makers in the population. 


\section{Procedures}

We went through several steps to ensure the credibility and validity of our experimental task. First, we explored several offerings of on-line and real-world PC vendors to select the total range of modules and module levels to be used in the experiment. A few weeks before the actual data collection, we conducted a pretest with the panel to validate that the range of levels we selected was realistic for respondents. At this stage, we also measured the panel members' selfreported level of expertise regarding PCs. These measures were later used in the estimation of the model.

Meanwhile, we developed an experimental website that approximated the experience a consumer would have when buying a mass customized PC on-line (in particular the 'Customize your Dell system' website). Like the Dell website, the experimental interface allowed consumers to choose their most preferred level from different modules and included as one of the manipulations, a base default version like Dell offers to its customers. The experimental mass customization interface was pre-tested off-line with several consumers and discussed with some PC experts as well as the consumer panel management who were experienced with on-line data collection. Based on the pre-test and discussions, some minor clarifications to the experiment were added, and a click-through 'help’ option was added that explained in general terms the function of the different modules that were presented and that was accessible at any stage of the experiment.

Then, the data for the experiment were collected. In the experiment, an introduction page explained the respondent's task and the various components of the PC that could be mass customized. This was followed by a practice task that all respondents had to complete. Next, each respondent had to mass customize a PC in eight different experimental conditions presented on different web pages. These eight conditions differed on the four mass customization factors 
(summarized in Tables 1a and 1b). A pull down menu showed all levels within each mass customizable PC module. To make sure that respondents were confronted with the different aspects of the mass customization configuration in each of the eight conditions we asked respondents to mass customize a PC in all the scenarios they faced. This task situation is similar in nature to a consumer using a website for example to find out what PC s/he could configure and how much it would cost. If a default was present, respondents could choose the default if they wished. They could do this immediately, but also after having 'tried' different mass customization configurations. They could not however revert to a standard default option once they had tried other options. In this case they had to compose the default version themselves. Prices were shown for all alternatives composed by the respondent and for the default. After respondents had selected their preferred PC, we measured respondents' product utility, complexity and mass customization utility.

\section{Independent variables}

In the experimental conditions, we manipulated four factors based on our hypotheses development (H3-H6): extent of mass customization (number of modules and number of levels per module), level heterogeneity, individual pricing of modules, and type and availability of a default version (see Table 1a). The levels were chosen to represent realistic options at the time. We manipulated all factors at two levels except for default version. This factor had three levels: a default could either be present or absent, and when present, have two levels, an advanced or base level. We also included a predefined part in the experiment that served as a baseline evaluation in the model.

Consumer expertise was measured using five aspects of consumer expertise about PCs (knowledgeable, competent, expert, trained, experienced) on a seven-point scale (for example, the measure for knowledge ranged from "not at all knowledgeable” to "very knowledgeable"). 
We adapted these measures of consumer expertise from Netemeyer and Bearden (1992) and the coefficient alpha showed very high reliability (0.97).

\section{Design}

A fractional factorial design prescribed the variations over experimental conditions. The design was a 32 profile fraction of a $4.2^{5}$ full factorial representing all mass customization options at 2 levels each with the exception of the default variable which varied on four levels (two out of the four levels represented 'no default', and the other two represented 'base default' and 'advanced default' respectively). We divided the total of 32 profiles systematically into four versions of eight profiles using an additional free 4 level factor that was also available in the 32 profile fraction. Each level of this factor represented one version of the survey. This procedure ensured that there was no confounding between versions and the other variables in the design, but does not allow one to estimate separate parameters for each version in the analysis. The profiles in each of the four versions were randomized and one practice task was added. We randomly assigned each respondent to one of the four versions of eight profiles.

\section{Dependent variables}

Our central variable of interest was the respondent's choice whether or not to use a certain mass customization configuration. Therefore, we asked respondents to choose whether or not they would use the mass customization configuration they had just used, if it were available in reality. In the model, this choice is explained on the basis of the underlying latent utility that the respondent attaches to using the mass customization configuration as is common in consumer choice modeling (e.g., Ashok, Dillon and Yuan 2002; McFadden 1986). As an indicator for product utility, we asked respondents to express the likelihood that they would purchase the product they selected if it were available in reality. This approach is common in previous research in conjoint analysis (e.g., Huber et al. 1993). The response was given on a scale that 
ranged from 0 to $100 \%$. To measure complexity, we used three ratings of the complexity of the configurations used to compose the PC - 'complicated', 'difficult' and 'effortful' - measured on a seven-point measurement scale. For example, the measure for 'complicated' ranged from "not at all complicated" to "very complicated". The coefficient alpha on this measure showed a high reliability of 0.91. Confirmatory factor analysis showed that our measures of expertise, product utility and complexity fitted well with three distinct factors.

\section{Model}

We first explain the model structure and specification, after which we discuss estimation.

\section{Model structure and specification}

We develop a model that captures how mass customization configuration and consumer expertise affect product utility and complexity and how these latter two constructs in turn affect mass customization utility (see Figure 1 for a graphical summary and Tables 2a and $2 \mathrm{~b}$ for notation). An intuitive starting point for understanding the proposed model structure is the mass customization choice model. By itself, this model is a traditional binary logit model of the consumer choice for the mass customization process. This choice is a function of the (latent) utility that the consumer obtains when s/he chooses to use the mass customization process. Next, in the model are a number of structural equations that relate the different latent variables and the experimental variables. To connect the observed measures to the underlying latent variables, the model structure also includes a set of measurement equations. Thus, our model specification integrates measures of consumer expertise, perceptual measures of complexity and product preference, all as explanatory variables in a discrete choice model for the mass customization configuration. 
To model the effect of these different types of behavioral components on consumer choice, we draw on a framework initially proposed by McFadden (1986) and later extended and implemented by Ben-Akiva et al. (1999) and Ashok, Dillon and Yuan (2002). This framework incorporates psychometric data in a consumer choice modeling context, which allows for simultaneous estimation across the different data types. We estimate an integrated multi-equation model consisting of a discrete choice model and a number of latent variable models. The approach results in estimates of the latent variables that provide the best fit with the information provided by both the observed choices and the indicators of the latent variables (i.e., complexity measures, a product utility measure and consumer expertise measures).

Thus, the model structure has three main sets of equations:

(1) The choice model for mass customization configuration. In this choice model, the individual's mass customization utility is a latent variable that drives the choice whether or not to use a certain mass customization configuration.

(2) A set of structural equations. These structural equations define the relationship between the latent variables in the model. A first structural equation defines the relationship between mass customization utility on the one hand and product utility and complexity on the other hand. A second structural equation explains product utility from two other latent variables (i.e. consumer expertise and complexity), and the mass customization factors. A third structural equation explains complexity from consumer expertise and the mass customization factors.

(3) A set of latent variable measurement equations. These measurement equations allow for identification of the latent variables. Note that in these measurement equations, the latent 
variable 'drives' the observed measures, similar to the way in which utility drives the consumer choice in the traditional choice models.

In developing the formal model structure, we start with the choice model part. First, we express $U M C_{c i}^{*}$, the utility of mass customization configuration $c$ to consumer $i$, as a function of product utility $\left(U P R O D_{c i}^{*}\right)$, complexity $\left(C O M P L_{c i}^{*}\right)$, and $\varepsilon_{M C c i}$, an individual and mass customization configuration specific error term that captures unexplained variation in consumers' choices due to measurement error and unobserved explanatory variables. To allow for differences between consumers we model the parameters $(\beta)$ in the model as random coefficients with their own error terms $(v)$. We allow for different variances for the error terms in the equation and assume that they are independent and normally distributed. ${ }^{3}$ Note that in our estimation this utility function drives the probability that a consumer chooses to use a given mass customization configuration or not when we assume that the error terms $\varepsilon_{M C c i}$ are independently and identically Gumbel distributed to obtain the well-known binary logit specification.

$$
U M C_{c i}^{*}=\alpha^{M C}+\left(\beta_{P R O D}^{M C}+v_{P R O D i}^{M C}\right) U P R O D_{c i}^{*}+\left(\beta_{C O M P L}^{M C}+v_{C O M P L i}^{M C}\right) C O M P L_{c i}^{*}+\varepsilon_{M C c i}
$$

Next, we express both product utility and complexity as a function of consumer expertise $\left(E X P_{i}^{*}\right)$ and a vector of mass customization configuration factors $\mathbf{C O N F}_{c}$. In the product utility model, we add to this specification the effect of complexity and allow for an interaction with consumer expertise. To control for further remaining heterogeneity we also include: (1) a variable that represents progress through the experiment to capture possible differences in product utility and complexity that may arise due to e.g., boredom, fatigue or learning in the

\footnotetext{
${ }^{3}$ Equations 2 and 3 follow the same structure and notation. We tested the assumption of independent errors in our application and it could not be rejected.
} 
experiment when individuals respond to multiple experimental scenarios (PROGRESS), (2) random coefficient parameters for the effects of the latent factors, mass customization configuration, and progress, and (3) significant interactions of expertise with experimental variables (i.e., extent of mass customization).

$$
\begin{aligned}
& U P R O D_{c i}^{*}=\alpha^{P R O D}+\left(\beta_{C O M P L}^{P R O D}+\beta_{E X P C O M P L}^{P R O D} E X P_{i}^{*}+v_{C O M P L i}^{P R O D}\right) C O M P L_{c i}^{*}+\left(\beta_{E X P}^{P R O D}+v_{E X P i}^{P R O D}\right) E X P_{i}^{*} \\
& +\left(\boldsymbol{\beta}_{\mathrm{CONF}}^{\mathrm{PROD}}+\boldsymbol{\beta}_{\mathrm{EXPCONF}}^{\mathrm{PROD}} E X P_{i}^{*}+\mathbf{v}_{\mathrm{CONFi}}^{\mathrm{PROD}}\right) \mathbf{C O N F} \mathbf{C N}_{c}+\gamma^{\text {PROD }} \text { PROGRESS }+\varepsilon_{\text {PROD } i} \\
& C O M P L_{c i}^{*}=\alpha^{C O M P L}+\left(\beta_{E X P}^{C O M P L}+v_{E X P i}^{C O M P L}\right) E X P_{i}^{*} \\
& +\left(\boldsymbol{\beta}_{\mathrm{CONF}}^{\mathrm{COMPL}}+\boldsymbol{\beta}_{\mathrm{EXPCONF}}^{\mathrm{COML}} E X P_{i}^{*}+\mathbf{v}_{\mathrm{CONFi}}^{\mathrm{COMPL}}\right) \mathbf{C O N F}_{c}+\gamma^{\text {COMPL }} \text { PROGRESS }+\varepsilon_{\text {COMPLCi }}
\end{aligned}
$$

Finally, we define three measurement equations to estimate parameters $(\lambda)$ that relate the observed measures of product utility, complexity and consumer expertise to their underlying latent constructs. We allow for different error variances $(\eta)$ for the different measures of each construct and assume independent normal distributions for each equation conditional on the latent constructs.

$$
\begin{gathered}
U P R O D_{c i}=\lambda_{P R O D} U P R O D_{c i}^{*}+\eta_{P R O D c i} \\
\mathbf{C O M P L}_{c i}=\lambda_{\mathrm{COMPL}} \operatorname{COMPL}_{c i}^{*}+\boldsymbol{\eta}_{\mathrm{COMPL} c i} \\
\mathbf{E X P}_{i}=\boldsymbol{\lambda}_{\mathrm{EXP}} E X P_{i}^{*}+\boldsymbol{\eta}_{\mathbf{E X P} i}
\end{gathered}
$$

\section{Estimation}

Appendix A describes the likelihood function we define for the model. We estimate the model using a smooth simulated maximum likelihood procedure (e.g., Train 2003). At the basis of this approach is the recognition that conditional on both the values of the latent constructs and the individual-specific errors our model is a traditional logit model. We can then express the unconditional likelihood as the expected value of the conditional contribution of each observation with the expectation taken over the joint density of the individual-specific error 
components and the distribution of the latent constructs. This is a multi-dimensional integral for which no analytical solution can be given. The simulated maximum likelihood procedure approximates the integral for each individual by a mean of simulated conditional likelihoods. Note that in our application we have several observations for each individual and that the individual random components in the random coefficients remain constant for the simulations for all observations from the same individual. The individual-level probabilities are then multiplied to obtain the total simulated maximum likelihood for all individuals. In our estimations, we based this simulated mean per individual for each of the random coefficients and the three latent constructs on 100 Halton draws. Halton sequences are designed to give an even coverage over the domain of the mixing distribution and therefore have better simulation properties than random draws. For example, Train (2003) reports results in which the simulation error in the estimation of a mixed logit model was lower with 100 Halton draws than with 1,000 random draws. We then transform these draws with different variance parameters to allow for estimation of differences in variance between random variables.

In this procedure, instead of the true likelihood, the simulated likelihood is maximized. It can be shown that this procedure is asymptotically equivalent to regular maximum likelihood procedures provided that the number of independent draws is large enough (e.g, Hajivassiliou and Ruud 1994). The latter result implies that standard ways of obtaining maximum likelihood estimates and standard errors can be used.

To test our estimation procedure, we examined its ability to capture correctly a set of prespecified parameter values in the model structure that we proposed. To do so, we generated synthetic data for the different measures and outcomes based on a known set of parameter values identical to the estimates from our application and using the same number of observations as in 
the application. In running our tests, we examined the estimation procedure's sensitivity to the number of draws in the simulation procedures. We compared the results of using 30, 50, 100 and 200 Halton draws.

The results of these tests indicated that the estimation procedure was able to reproduce the original values at 100 and 200 Halton draws, but did not do as well at 30 or 50 draws. Performance of the estimation procedure for 100 and 200 draws was very similar. We observed that the model estimates of the standard deviations of the random coefficients were most sensitive and could only be recovered well if starting values were used that were close to the original values. This sensitivity did not decrease when moving from 100 to 200 draws, but largely disappeared when we ran an additional test with twice the number of observations and 100 Halton draws. On this basis, we conclude that the estimation procedure worked well, but that the random coefficient standard deviation parameters in our application may need to be interpreted with some caution.

\section{Results}

Tables 2a, 2b and 2c present the estimation results for our model. Although we estimated all model parameters simultaneously, we present separate tables for expositional clarity. Table 3 summarizes our results in terms of the hypotheses and Table 4 provides summary statistics of the experiment. On average across all scales, respondents rated themselves with 3.9 out of 7 (s.d. 1. 7) on our five different expertise scales (that ranged from 1 to 7 with increasing expertise). The average perceived mass customization complexity was 2.9 out of 6 (s.d. 1.9) across the three perceived complexity scales (that ranged from 0 to 6 with increasing complexity). The average reported product utility as measured by the likelihood of buying the PC was 32.3 percent. The average number of responses per scenario was 75.7 and across all experimental scenarios 
respondents chose to use the mass customization configuration in 25.8 percent of the cases. The number of yes responses per scenario ranged between 12 (out of 80) for the least attractive scenario and 29 (out of 85 ) for the most attractive one.

We now summarize the results for our hypotheses.

- As expected, product utility has a strong and positive effect on mass customization utility while complexity has a negative effect. These findings support our hypotheses (H1a and H1b).

- We also find support for our hypothesis that higher complexity in mass customization does not only affect mass customization utility directly, but also indirectly through its negative effect on product utility (H2).

- We find support for the hypothesis that the higher the extent of mass customization (i.e. the higher the number of mass customizable modules and the number of levels per module), the higher consumers’ product utility (H3a). Somewhat surprisingly, we find that extent of mass customization does not have a significant effect on consumers’ complexity (H3b). Neither increasing the number of mass customizable modules nor the number of levels per module increases consumers’ complexity.

- We also observe that, as hypothesized (H4a), the more heterogeneous the different levels for a mass customizable module are, the lower product utility. We do not find an effect on complexity (H4b).

- We find support for the hypothesis (H5a) that individual pricing of modules negatively affects product utility. Furthermore we find that individual pricing increases complexity (H5b).

- In line with what was hypothesized (H6), we find that providing a 'base' default version (low-end PC) leads to a higher product utility than providing an 'advanced' default version (high-end PC).

- As to consumer expertise, we find support for the hypothesized negative effect of consumer expertise on complexity (H7).

- Finally, we observe that higher consumer expertise reduces the negative effect of complexity on product utility, which is also as hypothesized (H8). 
Note that we capture consumer heterogeneity in the model in several ways. First, we introduce the effect of consumer expertise in different parts of the model. We find significant effects as hypothesized. A second way in which we capture heterogeneity in the model is by estimating random coefficients for the parameters in the model that define product utility and complexity. Here, we find significant heterogeneity on all parameters for the latent variables in the model (i.e., the effect of complexity on product utility and the effect of expertise). We find only one mass customization parameter with significant heterogeneity for product utility and three for complexity. Apparently in the context of our experiment the impact of mass customization configuration on product utility and complexity differs relatively little between consumers. Third, we also allow for heterogeneity in the measurement equations for product utility, complexity and consumer expertise by estimating different standard deviations for all measurement scales that we used. These standard deviations all are significant and are reported in Table 2c. Fourth, we allow for unexplained heterogeneity in the core structure of our model by estimating different random error variations in the product utility and complexity models. These effects are also significant. Finally, we also controlled for respondents’ progress through the experiment. We found that as respondents progressed, both product utility and complexity decreased, the former possibly due to boredom or fatigue, the latter more likely due to learning.

\section{Further analyses}

We conducted further analyses to assess the robustness of our findings. More in particular, we estimated alternative model specifications and considered additional default options. 


\section{Alternative model specifications}

We compared the proposed model to two nested model specifications (a model without random coefficients and a model in which the effect of consumer expertise was not included), and two non-nested specifications (a model that did not include complexity and a model in which neither complexity nor product utility were included). We found that in all specifications parameter estimates were identical in sign and had similar effects as in the proposed model. A log-likelihood ratio test revealed that the proposed model outperformed both nested alternatives ( $\mathrm{p}<0.01$ ) and a comparison of CAIC scores showed that it also outperformed the two non-nested alternatives.

We also investigated if an alternative explanation for the observed effect of complexity on product utility could be a moderating effect of complexity on the relationship between product utility and mass customization utility. We estimated a model including both effects and found our earlier results to be robust to the additional moderating effect. The moderating effect itself was also significant. A more detailed investigation of this effect suggested that consumers are more willing to accept the complexity of a mass customization configuration if the configuration allows them to achieve a higher product utility. This finding may perhaps be explained by a residual-desire effect as proposed by Heath et al. (2000). These authors suggest that when consumers trade off product quality loss and price, they are more concerned about forgone product quality than forgone monetary costs. A similar effect could occur in the tradeoff of product utility and effort, and consumers could be more willing to trade-off effort for product utility than vice versa, making them less sensitive to complexity when product utility is high. 


\section{The role of the default in mass customization participation utility}

One important restriction of our experimental design was that in order to have control over the type of default version that respondents faced, we provided them with only one default version. This default option was either a base version or an advanced version. In the real world, however, firms often provide consumers with a number of defaults, for example by allowing consumers to first select a PC product type that is roughly in line with their preferences and then specify their most preferred configuration within this product line (cf. Dell on-line). This business practice may be helpful to consumers if they can select a default version that is close to their preferences, and compose their PC starting from this default version.

This default structure may affect complexity and product utility. We expect that consumers that are presented with a default version that is close to their preferred PC configuration have a lower complexity, because they have to go through a smaller number of cognitive steps to configure their most preferred product. Consumers' product utility may also be affected by the type default version they see because they need to 'upgrade' less from a PC that is already closer to their most preferred option. We expect that most consumers' preferred configuration is somewhere in between a base and an advanced version. Since in our main study we observed that product utility is highest when consumers upgrade from a base default version and is lowest when they downgrade from an advanced default version, we expect that their product utility is at an intermediate level if they are faced with a default version that is close to their most preferred PC.

Presenting consumers with multiple defaults also introduces a number of additional cognitive steps that consumers have to go through when making their mass customization decisions and thus increases perceived complexity (Bettman, Johnson and Payne 1990). The reason is that before they can put together their PC they first have to compare between different 
PC types and choose the one type they prefer. Furthermore, if respondents don't wish to decide on a PC type, they are forced to switch back and forth between PC configurations across the different types. Such comparisons require additional effort from the consumer relative to choosing a PC configuration within only one type that includes all possible modules and levels. Thus, we expect comparisons across PC types to increase complexity.

To explore these possible effects of introducing an intermediate default version and multiple defaults we conducted a second follow-up experiment. Participants in this experiment were students at the first author's university who participated in return for a cash payment (in the pre-test) and a lottery to win a CD or DVD voucher (in the actual experiment). To set up this experiment, we copied the three default PC versions available at the Dell website at the time. We copied all modules and levels as they were available. In setting up this experiment, we first explored with a sample of 52 students which of the three default versions was most popular. We found that the intermediate default version was most attractive, with the base default version as a good second. Only very few respondents preferred the advanced default.

Next, we designed an on-line computer experiment that had 5 default versions. Versions 1, 2 and 3 had only one default, which was a base, intermediate and advanced default respectively. In version 4 all these three default versions (base, intermediate and advanced) were first shown and briefly described on a separate screen (again mimicking the Dell website), after which respondents could mass customize their PC within the PC type they preferred. Version 5 had no default and all modules with all levels were shown directly to respondents.

In line with our main study, respondents were first shown an introductory screen explaining the task and then were asked to construct their most preferred PC. Respondents were only shown one mass customization scenario that represented one of the five versions and were 
randomly assigned across versions. After choosing a PC configuration they were asked about their complexity, the utility of the product they had selected, and their mass customization utility.

We first pre-tested the experiment off-line with a number of respondents before collecting data on-line and discussed its structure with the manager of the panel and a number of knowledgeable PC users. For the full study, 224 respondents participated within the six-week response period we had set, in response to an e-mail to participants in an on-line student panel and course participants (approximately 900 individuals in total). An exploratory factor analysis of the responses showed that they loaded clearly on three different factors. We then ran a second factor analysis on the responses for each of the constructs separately, obtaining factor scores for each of the three constructs. To test for differences between the five versions, we conducted a MANOVA comparing the mean scores for each of the factors across the versions. The results are summarized in Table 4.

We find that, as expected, offering an intermediate level default version leads to the lowest level of complexity. This level is significantly lower $(\mathrm{p}<0.05)$ than the level of complexity if an advanced default version is offered or if three default versions are offered. Thus, only if one offers a default that matches consumers' preferences does this significantly decrease complexity, but offering non-matching defaults or even multiple defaults - including one that matches consumers' preferences - does not decrease complexity. This is an interesting further refinement of our findings in the main study in which we observed that the effect of offering either a base or an advanced default did not decrease complexity.

The results of the second experiment support our findings with regard to the effect of a base vs. advanced default on product utility. Respondents reported the highest product utility level when presented with a base default. This product utility was significantly higher (at $\mathrm{p}<$ 
0.05) from that reported when an advanced default version was offered, or if no or three default versions were offered. Product utility was at an intermediate level if the (most popular) intermediate default version was offered.

Finally, we ran a regression analysis of product utility and complexity on mass customization utility (Adj. R-sq. of 0.124). The results of this analysis showed that as in the main study product utility had a significant positive effect on mass customization utility $(\mathrm{p}<0.00)$, while complexity had a significant negative effect $(\mathrm{p}<0.00)$.

\section{Discussion}

We can summarize the results of the study as follows. We find that mass customization configuration affects the product utility consumers can achieve in mass customization, as well as their perception of mass customization complexity. In turn, product utility and complexity affect the utility consumers derive from using a certain mass customization configuration. More specifically, product utility has a positive and complexity has a negative effect on mass customization configuration utility. The effect of complexity is direct as well as indirect, because complexity also lowers product utility.

\section{Managerial implications}

In terms of extent of mass customization, we find that within the rather large range of modules and module levels we manipulated in this study, consumers did not perceive significant increases in complexity, while they were indeed able to achieve higher product utility. This is good news for those who wish to provide many options to consumers. We also found that the negative effects of complexity on mass customization utility are lower for expert consumers, making them a potentially attractive target segment for mass customization.

Within the context of our experiment, we found that firms can benefit from introducing extensive mass customization using a carefully designed mass customization configuration. 
Three features deserve some more attention. First, our results imply that firms when increasing the number of module levels, should typically offer consumers more additional options in the most popular range of a module and less additional options at the extremes. Second, pricing should preferably be presented only at the total product level, rather than at the module and product level. We find that this approach reduces complexity and increases product utility. Third, firms should offer a default version that consumers can use as a starting point for mass customization, as doing so minimizes the complexity to consumers. The best default version to start out with is a base default version because this type of default version allows the consumer to most closely approach his or her ideal product. The reason is that consumers when presented with an advanced default may buy a product that is more advanced than they actually need..

We also find that simplifying a mass customization process not only increases the probability of choosing this process, but also the product utility in the process. This suggests that easy-to-use mass customization processes can also be used as a tool in achieving greater product appreciation and in the long term possibly higher customer loyalty. From a managerial perspective, this may be an interesting area of future investigation.

\section{Limitations and future research}

Some limitations of our study are worth noting. Consumers in our experiment made hypothetical mass customization decisions and reported in terms of their intended use of a mass customization configuration in only one product context. Though we used real consumers in our study and took great care in developing realistic experimental conditions, consumers' decisions in the real world and/or for other product categories may differ. Moreover, we found evidence of learning as consumers progressed through the experiment. It would be worthwhile to test our model in other contexts to see if these effects we observed are generalizable. 
Nevertheless we hope that our research can be a starting point for further research in marketing on mass customization. We outline some promising areas for future research that also reveal further limitations of our study. Since our research focuses on consumers' utility for different mass customization configurations, we do not address the question how consumers choose between buying a mass customized product and buying a standardized product available in the market. It would be quite relevant to study the question how consumers' choices to mass customize or not can be modeled.

There also are several aspects in our model that warrant more detailed future research especially at the level of consumer information processing. For example, complexity may have more the character of an individual trait than a task-specific effect, which could explain why the extent of mass customization has little impact on complexity. Another question regarding complexity that remains open for further investigation, is if perhaps the relationship between product utility and complexity could be reversed. It is possible that consumers that don't obtain the product that they want, report that a mass customization configuration is complex. In our analysis in contrast we have assumed that complexity reduces product utility.

Variations in consumers' decision strategies regarding different aspects of mass customization configurations would also constitute an interesting area for further research. For example, different consumers may process individual prices and default suggestions differently. Furthermore, it would be interesting to investigate the degree to which consumers enjoy mass customizing a product. Research on self-service technology (Dabholkar and Bagozzi 2002) suggests that this may be the case and it would be interesting to see if this effect translates into consumers’ utility for mass customization configurations. 
Finally, we believe it would be worthwhile to establish an evaluation criterion that is external to the mass customization configuration and that could be used to study if consumers buy 'better' or 'worse' products when they mass customize than when they choose between standardized products. A possible candidate for such a criterion could be consumers’ product satisfaction measured after a certain period of use. Thus, we hope the present study stimulates more marketing research into the vastly understudied phenomenon of mass customization. 
Table 1A:

Mass customization configuration factors as manipulated in the experiment

\begin{tabular}{|c|c|c|}
\hline Characteristic & Levels & Description \\
\hline \multicolumn{3}{|l|}{ Extent of mass customization } \\
\hline \multirow[t]{2}{*}{ Number of mass customizable modules } & Low & 4 (Processor, Monitor, Memory and Hard drive) \\
\hline & High & $\begin{array}{c}8 \text { (Processor, Monitor, Memory, Hard drive, Mouse, } \\
\text { Keyboard, Video card and Speakers) }\end{array}$ \\
\hline \multirow[t]{2}{*}{$\begin{array}{l}\text { Number of levels per mass customizable } \\
\text { module* }\end{array}$} & Low & $\begin{array}{c}4 \text { (for first four modules); } \\
2 \text { (for second four modules) }\end{array}$ \\
\hline & High & $\begin{array}{l}8 \text { (for first four modules); } \\
4 \text { (for second four modules) }\end{array}$ \\
\hline \multirow{9}{*}{ Level heterogeneity } & & Module levels included (ranked from 1 to 15 ) \\
\hline & Low & $4,5,6,7$ \\
\hline & & $4,5,6,7,8,9,10,11$ \\
\hline & & $4,5,6,7$, and 2,3 \\
\hline & & $4,5,6,7,8,9,10,11$ and $2,3,4,5$ \\
\hline & High & $3,5,7,9$ \\
\hline & & $1,3,5,7,9,11,13,15$ \\
\hline & & $3,5,7,9$ and 1,3 \\
\hline & & $1,3,5,7,9,11,13,15$ and $1,3,5,7$ \\
\hline \multirow[t]{2}{*}{ Individual pricing of modules } & Individual & Price is given per module level and at the product level \\
\hline & Combined & Price is given only at the product level \\
\hline \multicolumn{3}{|l|}{ Default version } \\
\hline Default present & $\begin{array}{l}\text { Yes } \\
\text { No }\end{array}$ & \\
\hline \multirow[t]{2}{*}{ Base vs. advanced default } & Base & Lowest quality level is given as default \\
\hline & Advanced & Highest quality level is given as default \\
\hline
\end{tabular}

* The first four modules were always included in the mass customization configuration; the second four modules were fixed in the 'low' number of mass customizable modules condition and could be mass customized in the 'high' number of mass customizable modules condition. 
Table 1B:

PC modules used in experiment

\begin{tabular}{|c|c|c|c|c|c|c|c|c|}
\hline levels & Processor & Monitor & Memory & Hard drive & Mouse & Keyboard & Video card & Speakers \\
\hline 1 & Intel Celeron 533Mhz & Philips 105/S 15" & $\begin{array}{l}32 \text { MB SD- } \\
\text { RAM }\end{array}$ & $\begin{array}{l}\text { 10,2 GB Maxtor Diamond- } \\
\text { max, } 5400 \text { rpm }\end{array}$ & $\begin{array}{l}\text { Microsoft } \\
\text { muis }\end{array}$ & BTC & $\begin{array}{l}\text { SIS } 6326 \\
4 \mathrm{MB}\end{array}$ & $\begin{array}{l}\text { Philips MMS110, 1,5 } \\
\text { watt }\end{array}$ \\
\hline 2 & Intel Celeron 600Mhz & Philips 107/E 17" & $\begin{array}{l}64 \text { MB SD- } \\
\text { RAM }\end{array}$ & $\begin{array}{l}\text { 15,3 GB Maxtor Diamond- } \\
\text { max, } 5400 \text { rpm }\end{array}$ & $\begin{array}{l}\text { Logitech } \\
\text { wheel muis }\end{array}$ & $\begin{array}{l}\text { Cherry G83- } \\
\quad 6104\end{array}$ & $\begin{array}{l}\text { SIS } 6326 \\
8 \mathrm{MB}\end{array}$ & $\begin{array}{c}\text { Philips MMS140, } 4 \\
\text { watt }\end{array}$ \\
\hline 3 & Intel Pentium III 600Mhz & Philips 107/B 17" & $\begin{array}{l}96 \text { MB SD- } \\
\text { RAM }\end{array}$ & $\begin{array}{l}\text { 15,3 GB Maxtor Diamond- } \\
\text { max+, } 7200 \text { rpm }\end{array}$ & $\begin{array}{l}\text { Logitech } \\
\text { pilot muis }\end{array}$ & $\begin{array}{l}\text { Microsoft } \\
\text { internet }\end{array}$ & $\begin{array}{l}\text { Diamond } \\
\text { Speedstar } \\
\text { A200 8MB }\end{array}$ & $\begin{array}{c}\text { Philips MMS230, } 6 \\
\text { watt }\end{array}$ \\
\hline 4 & AMD Athlon (K7) 650Mhz & $\begin{array}{l}\text { iiyama S704HT Vision } \\
\text { Master } 404 \text { 17" }\end{array}$ & $\begin{array}{l}128 \text { MB SD- } \\
\text { RAM }\end{array}$ & $\begin{array}{l}\text { 20,4 GB Maxtor Diamond- } \\
\text { max, } 5400 \text { rpm }\end{array}$ & $\begin{array}{l}\text { Microsoft } \\
\text { Intelli-mouse }\end{array}$ & $\begin{array}{l}\text { Microsoft } \\
\text { internet } \\
\text { valuepack }\end{array}$ & $\begin{array}{c}\text { Diamond } \\
\text { Speedstar } \\
\text { A90 16MB }\end{array}$ & $\begin{array}{c}\text { Labtec LCS } 2408 \\
\text { universal subwoofer, } \\
6,5 \text { watt }\end{array}$ \\
\hline 5 & Intel Pentium III 650Mhz & $\begin{array}{c}\text { iiyama A702HT } \\
\text { Vision Master Pro } 410 \\
\text { 17" }\end{array}$ & $\begin{array}{l}192 \text { MB SD- } \\
\text { RAM }\end{array}$ & $\begin{array}{l}\text { 20,4 GB Maxtor Diamond- } \\
\text { max+, } 7200 \text { rpm }\end{array}$ & $\begin{array}{l}\text { Logitech } \\
\text { trackball } \\
\text { marble wheel }\end{array}$ & $\begin{array}{l}\text { Microsoft } \\
\text { natural elite }\end{array}$ & $\begin{array}{l}\text { MSI-8808 } \\
\text { Riva TNT2 } \\
\text { M64 32MB }\end{array}$ & $\begin{array}{l}\text { Labt LCS } 2514 \text { 4- } \\
\text { point surround incl. } \\
\text { subwoofer, } 6,5 \text { watt }\end{array}$ \\
\hline 6 & AMD Athlon (K7) 700Mhz & $\begin{array}{l}\text { Philips 107/P10 } \\
\text { brilliance 17" }\end{array}$ & $\begin{array}{l}128 \text { MB RD- } \\
\text { RAM }\end{array}$ & $\begin{array}{l}\text { 9,1 GB Quantum Atlas IV, } \\
7200 \mathrm{rpm}\end{array}$ & $\begin{array}{l}\text { Logitech } \\
\text { cordless } \\
\text { wheel mouse }\end{array}$ & $\begin{array}{l}\text { Cherry G81- } \\
3000\end{array}$ & $\begin{array}{l}\text { Diamond } \\
\text { Viper II Z200 } \\
\text { 32MB }\end{array}$ & $\begin{array}{c}\text { Philips MMS320 } \\
\text { incl. subwoofer, } 10 \\
\text { watt }\end{array}$ \\
\hline 7 & Intel Pentium III 700Mhz & Philips 109/E 19" & $\begin{array}{l}256 \text { MB SD- } \\
\text { RAM }\end{array}$ & $\begin{array}{l}\text { 30,7 GB Maxtor Diamond- } \\
\text { max , } 5400 \text { rpm }\end{array}$ & $\begin{array}{l}\text { Microsoft } \\
\text { Intelli-mouse } \\
\text { explorer }\end{array}$ & $\begin{array}{l}\text { Logitech } \\
\text { desktop } \\
\text { cordless } \\
\text { itouch }\end{array}$ & $\begin{array}{c}\text { Matrox G400 } \\
\text { SG-Ram } \\
\text { Dual Head } \\
\text { 32MB }\end{array}$ & $\begin{array}{l}\text { Labtec EDGE } 418 \\
\text { flat panel incl. } \\
\text { subwoofer, } 10 \text { watt }\end{array}$ \\
\hline 8 & Intel Pentium III 750Mhz & $\begin{array}{c}\text { iiyama A901HT } \\
\text { Vision Master Pro } 450 \\
\text { 19" }\end{array}$ & $\begin{array}{l}128 \text { MB RD- } \\
\text { RAM with } \\
\text { ECC }\end{array}$ & $\begin{array}{l}\text { 30,7 GB Maxtor Diamond- } \\
\max ^{+}, 7200 \mathrm{rpm}\end{array}$ & & & & \\
\hline 9 & AMD Athlon (K7) 850Mhz & Philips 109/B XSD & $\begin{array}{l}384 \text { MB SD- } \\
\text { RAM }\end{array}$ & $\begin{array}{l}\text { 40,9 GB Maxtor Diamond- } \\
\text { max, } 5400 \text { rpm }\end{array}$ & & & & \\
\hline 10 & Intel Pentium III 800Mhz & $\begin{array}{c}\text { Philips 109/P10 } \\
\text { Brilliance 19" }\end{array}$ & $\begin{array}{l}256 \text { MB RD- } \\
\text { RAM }\end{array}$ & $\begin{array}{l}\text { 40,9 GB Maxtor Diamond- } \\
\max ^{+}, 7200 \mathrm{rpm}\end{array}$ & & & & \\
\hline 11 & AMD Athlon (K7) 900Mhz & $\begin{array}{c}\text { iiyama A201HT } \\
\text { VisionMaster Pro } 510 \\
\text { 22" }\end{array}$ & $\begin{array}{l}512 \text { MB SD- } \\
\text { RAM }\end{array}$ & $\begin{array}{c}\text { 18,2 GB Quantum Atlas IV, } \\
7200 \mathrm{rpm}\end{array}$ & & & & \\
\hline 12 & Intel Pentium III 850Mhz & $\begin{array}{l}\text { Philips 150B TFT- } \\
\text { LCD 15,1" }\end{array}$ & $\begin{array}{l}256 \text { MB RD- } \\
\text { RAM with } \\
\text { ECC }\end{array}$ & $\begin{array}{l}75 \text { GB Maxtor Diamond- } \\
\text { max, } 5400 \text { rpm }\end{array}$ & & & & \\
\hline 13 & AMD Athlon (K7) 1Ghz & $\begin{array}{l}\text { iiyama TXA3812JT } \\
\text { 15,1" TFT-LCD }\end{array}$ & $\begin{array}{l}384 \text { MB RD- } \\
\text { RAM }\end{array}$ & $\begin{array}{l}75 \text { GB Maxtor Diamond- } \\
\text { max+, } 7200 \text { rpm }\end{array}$ & & & & \\
\hline 14 & Intel Pentium III 933 Mhz & Philips 201/B 21" & $\begin{array}{l}384 \text { MB RD- } \\
\text { RAM with } \\
\text { ECC }\end{array}$ & $\begin{array}{l}\text { 36,4 GB Quantum Atlas IV, } \\
7200 \mathrm{rpm}\end{array}$ & & & & \\
\hline 15 & Intel Pentium III 1 Ghz & $\begin{array}{l}\text { Philips 150P Brilliance } \\
\text { TFT-LCD 15,1" }\end{array}$ & $\begin{array}{l}512 \text { MB RD- } \\
\text { RAM }\end{array}$ & $\begin{array}{l}45 \text { GB Quantum Atlas IV, } \\
7200 \mathrm{rpm}\end{array}$ & & & & \\
\hline
\end{tabular}




\section{Table 2A:}

\section{Mass customization choice model: drivers of mass customization utility}

\section{Parameter t-value}

\section{Effects on mass customization utility}

Intercept $\left(\alpha^{M C}\right)$

$-4.320$

$-22.674 *$

Product utility $\left(\beta_{P R O D}^{M C}\right)$

6.095

$14.646^{*}$

Random coefficient s.d.

8.597

18.759*

Complexity ( $\left.\beta_{C O M P L}^{M C}\right)$

$-0.430$

$-7.696 *$

Random coefficient s.d.

0.210

21.017*

$\mathrm{N}=409$ (total number of observations is 2427)

* significant at the 95\% confidence level. 


\section{Table 2B:}

\section{Mass customization choice model: latent and experimental variables}

\begin{tabular}{|c|c|c|c|c|}
\hline & \multicolumn{2}{|c|}{$\begin{array}{c}\text { Effect on } \\
\text { product utility }\end{array}$} & \multicolumn{2}{|c|}{$\begin{array}{l}\text { Effect on } \\
\text { complexity }\end{array}$} \\
\hline & Parameter & t-value & Parameter & t-value \\
\hline \multicolumn{5}{|l|}{ Latent variables } \\
\hline Variable level intercept ( $\alpha^{P R O D}$ and $\alpha^{C O M P L}$ ) & 0.388 & $64.217^{*}$ & -0.449 & $-19.362 *$ \\
\hline Random coefficient s.d. & 0.200 & 63.933* & 1.436 & $45.580^{*}$ \\
\hline Complexity $\left(\beta_{C O M P L}^{P R O D}\right)$ & -0.019 & $-9.667 *$ & N/A & N/A \\
\hline Random coefficient s.d. & 0.041 & $21.017 *$ & N/A & N/A \\
\hline Complexity $*$ Consumer expertise $\left(\beta_{\text {EXPCOMPL }}^{\text {PROD }}\right)$ & 0.011 & $5.664 *$ & N/A & N/A \\
\hline Consumer expertise $\left(\beta_{E X P}^{P R O D}\right.$ and $\left.\beta_{E X P}^{C O M P L}\right)$ & 0.040 & $12.062 *$ & -0.743 & $-42.752 *$ \\
\hline Random coefficient s.d. & 0.088 & $32.154 *$ & 0.044 & $4.450 *$ \\
\hline \multicolumn{5}{|l|}{ Mass customization configuration ${ }^{\mathfrak{k}}$} \\
\hline Number of modules & 0.016 & $4.767^{*}$ & 0.011 & 0.843 \\
\hline Random coefficient s.d. & 0.009 & $2.277^{*}$ & 0.029 & $1.974 *$ \\
\hline $\begin{array}{l}\text { Number of levels } \\
\text { Random coefficient s.d. }\end{array}$ & $\begin{array}{l}0.007 \\
0.008\end{array}$ & $\begin{array}{l}1.507 \\
1.620\end{array}$ & $\begin{array}{c}-0.018 \\
0.007\end{array}$ & $\begin{array}{c}-1.246 \\
0.460\end{array}$ \\
\hline Level heterogeneity & -0.012 & $-3.451^{*}$ & 0.011 & 0.762 \\
\hline Random coefficient s.d. & 0.002 & 0.349 & 0.038 & $2.103^{*}$ \\
\hline Individual pricing of modules & -0.009 & $-2.057 *$ & 0.048 & $3.565^{*}$ \\
\hline Random coefficient s.d. & 0.002 & 0.328 & 0.048 & $3.434 *$ \\
\hline Default version provided & -0.012 & $-2.659 *$ & 0.004 & 0.265 \\
\hline Random coefficient s.d. & 0.004 & 0.746 & 0.004 & 0.217 \\
\hline Base vs. advanced default version & 0.025 & $4.463^{*}$ & -0.014 & -0.695 \\
\hline Random coefficient s.d. & 0.002 & 0.390 & 0.012 & 0.536 \\
\hline Utility of predefined part & -0.004 & -1.101 & 0.011 & 0.835 \\
\hline Random coefficient s.d. & 0.002 & 0.333 & 0.013 & 0.727 \\
\hline \multicolumn{5}{|l|}{$\mathrm{N}=409$ (total number of observations is 2427) } \\
\hline
\end{tabular}


Table 2C

\section{Estimates of measurement equations *}

\begin{tabular}{lcccc}
\hline & Parameter & t-value & $\begin{array}{c}\text { Standard } \\
\text { deviation }\end{array}$ & t-value \\
\hline $\begin{array}{l}\text { Product utility } \\
\text { Scale 1 }\end{array}$ & Fixed to 1 & & 0.175 & 103.856 \\
& & & \\
Complexity & & & & \\
Scale 1 & Fixed to 1 & & 1.050 & 74.162 \\
Scale 2 & 1.041 & 27.422 & 0.995 & 85.581 \\
Scale 3 & 0.696 & 31.808 & 1.501 & 95.936 \\
& & & & \\
Consumer expertise & & & & \\
Scale 1 & Fixed to 1 & & 0.973 & 16.843 \\
Scale 2 & 1.458 & 23.565 & 0.735 & 19.447 \\
Scale 3 & 1.447 & 24.747 & 0.731 & 18.872 \\
Scale 4 & 1.426 & 21.541 & 0.819 & 23.009 \\
Scale 5 & 1.392 & 19.202 & 0.869 & 21.740 \\
& & & & \\
\hline
\end{tabular}

* All t-values are significant at the 0.95 confidence level. One of the parameters in each measurement equation was fixed to a value of one in the estimation for model identification purposes. $\mathrm{N}=409$. 


\section{Table 3:}

\section{Hypothesized effects and results}

\begin{tabular}{lcc}
\hline Hypothesis & $\begin{array}{c}\text { Hypothesized } \\
\text { effect }\end{array}$ & Result \\
\hline H1a: Product utility on mass customization utility & + & Supported \\
H1b: Complexity on mass customization utility & - & $\begin{array}{c}\text { Supported } \\
\text { Supported }\end{array}$ \\
H2: Complexity on product utility & - & Supported \\
H3a: The extent to which products can be mass customized on & + & Rejected \\
product utility & + & Supported \\
H3b: The extent to which products can be mass customized on & & Rejected \\
complexity & - & Supported \\
H4a: Heterogeneity in module levels on product utility & + & Supported \\
H5a: Individual pricing of modules on product utility & - & Supported \\
H5b: Individual pricing of modules on complexity & + & Supported \\
H6: Offering a base vs. an advanced default version on & + & Supported \\
product utility & - & \\
H7: Consumer expertise on complexity & + & \\
H8: Consumer expertise on the negative effect of complexity & & \\
\hline
\end{tabular}




\section{Table 4:}

\section{Summary statistics of the experiment}

\begin{tabular}{lcc}
\hline & & $s . d$. \\
\hline $\begin{array}{l}\text { Average expertise rating } \\
(1-7 \text { scale) }\end{array}$ & 3.9 & 1.7 \\
$\begin{array}{l}\text { Average complexity rating } \\
(0-6 \text { scale) }\end{array}$ & 2.9 & 1.9 \\
$\begin{array}{l}\text { Average product utility } \\
\text { (likelihood of buying 0-100\%) }\end{array}$ & 32.3 & \\
$\begin{array}{l}\text { Average number of responses per } \\
\text { configuration scenario }\end{array}$ & 75.7 & \\
$\begin{array}{l}\text { Average percentage of use for } \\
\text { configurations }\end{array}$ & 25.8 & \\
\hline
\end{tabular}


Table 5:

Results second experiment: The role of the default version ${ }^{\circ}$

\begin{tabular}{lccc}
\hline Scenarios & $\begin{array}{c}\text { Product } \\
\text { utility }\end{array}$ & Complexity & $N$ \\
\hline Base default version & $\mathbf{0 . 3 1 7}$ & 0.039 & 61 \\
Intermediate default version & 0.141 & $-\mathbf{0 . 2 8 1}$ & 46 \\
Advanced default version & $-0.126^{\S}$ & $0.176^{\S}$ & 37 \\
$\begin{array}{l}\text { Three default versions offered as } \\
\text { intermediate step }\end{array}$ & $-0.312^{\S}$ & $0.269^{\S}$ & 41 \\
No default version offered & $-0.214^{\S}$ & -0.179 & 39 \\
& & & \\
\hline
\end{tabular}

* significantly worse than proposed model at the 95\% confidence level.

o Table reports factor scores, best scoring default version in bold italics: lower complexity and greater product utility are more attractive

${ }^{\S}$ significantly worse than best scoring default version $(\mathrm{p}<0.05)$, based on MANOVA results 
Figure 1:

Mass customization utility model*

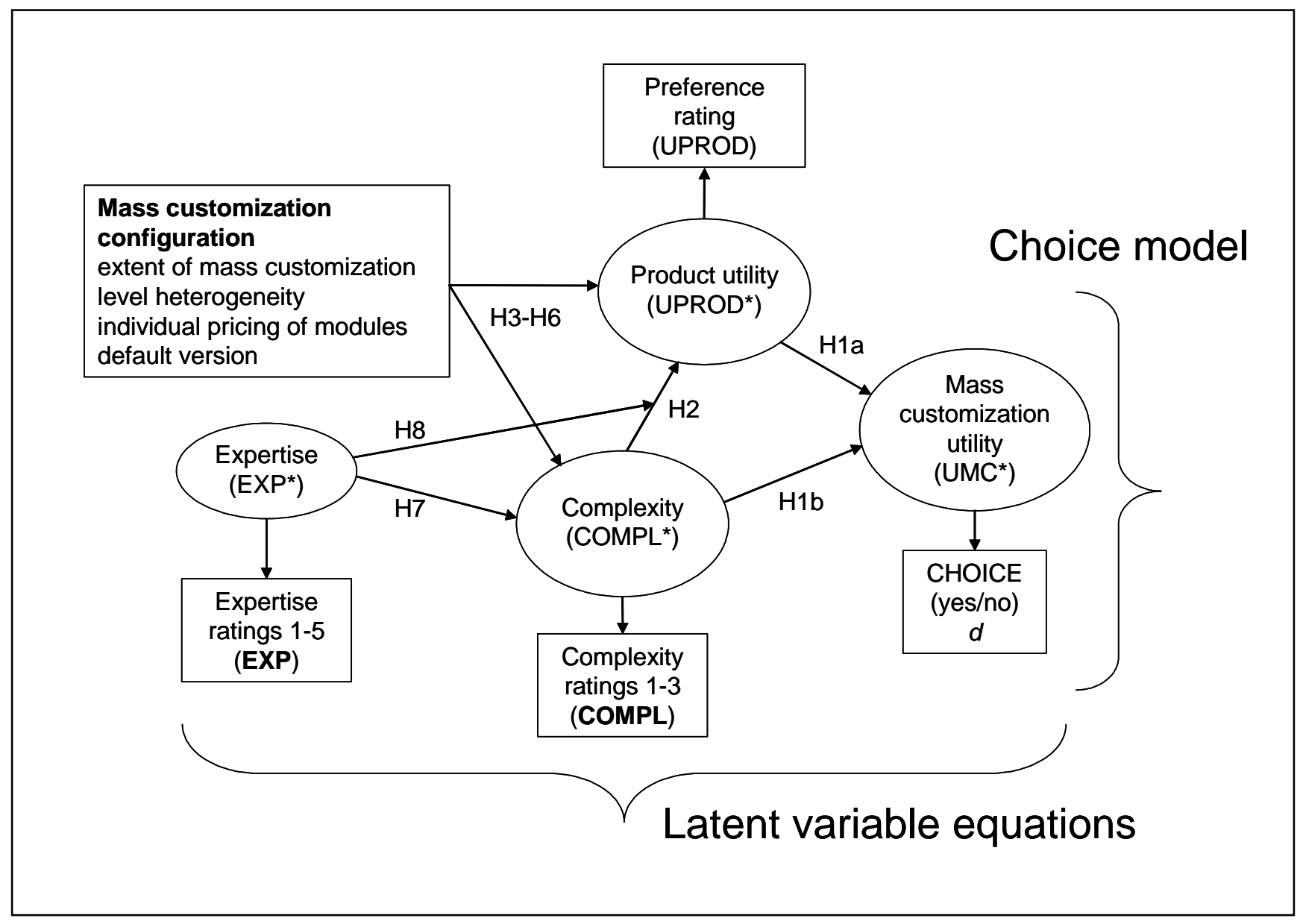

* Note: In this figure rectangular boxes represent the observed measures and the factors manipulated in the experimental study and circular boxes represent the underlying latent constructs. Arrows running from left to right represent hypothesized relationships, where an arrow between boxes represents a hypothesized main effect and an arrow pointing at another arrow represents a hypothesized interaction effect. Vertical arrows represent measurement relationships. 


\section{Appendix A}

To write out the likelihood function for the total model, we first define the likelihood of an individual's mass customization participation choice model without considering the latent variables (Ben-Akiva et al. 1999). For notational simplicity we omit the individual subscript $i$. Note that we estimate the random coefficients in the model by a simulated maximum likelihood procedure based on this likelihood function.

$$
P\left(d \mid U P R O D_{c}, \mathbf{C O M P L}_{c}, \mathbf{E X P}, \mathbf{E X T}_{c}, \mathbf{D E S}_{c}, T ; \alpha^{M C}, \beta_{P R O D}^{M C}, \beta_{C O M P L}^{M C}, \sigma_{\varepsilon M C}\right)
$$

In equation (A1) $d$ represents a dummy variable that takes on the value of 1 if the consumer chooses to participate in the mass customization process and 0 otherwise.

Then, the latent variables are added. The likelihood function is then the integral of the choice model over the distribution of the latent constructs, given the observed variables and taking into account for each latent construct the other latent constructs.

$$
\begin{aligned}
& P\left(d \mid U P R O D_{c}, \text { COMPL }{ }_{c}, \text { EXP }, \text { EXT }_{c}, \text { DES }_{c}, T ; \alpha^{M C}, \beta_{P R O D}^{M C}, \beta_{C O M P L}^{M C},\right. \\
& \alpha^{P R O D}, \beta_{\text {COMPL }}^{P R O D}, \beta_{\text {EXPCOMPL }}^{P R O D}, \beta_{\text {EXP }}^{P R O D}, \boldsymbol{\beta}_{\text {EXT }}^{\text {PROD }}, \boldsymbol{\beta}_{\text {EXPEXT }}^{\text {PROD }}, \boldsymbol{\beta}_{\text {DES }}^{\text {PROD }}, \beta_{T}^{P R O D} \\
& \left.\alpha^{C O M P L}, \beta_{E X P}^{C O M P L}, \boldsymbol{\beta}_{\text {EXT }}^{\text {COMPL }}, \boldsymbol{\beta}_{\text {EXPEXT }}^{\text {COMPL }}, \boldsymbol{\beta}_{\text {DES }}^{\text {COMPL }}, \beta_{T}^{C O M P L}, \sigma_{\varepsilon M C}, \sigma_{\varepsilon P R O D}, \sigma_{\varepsilon C O M P L}\right) \\
& =
\end{aligned}
$$

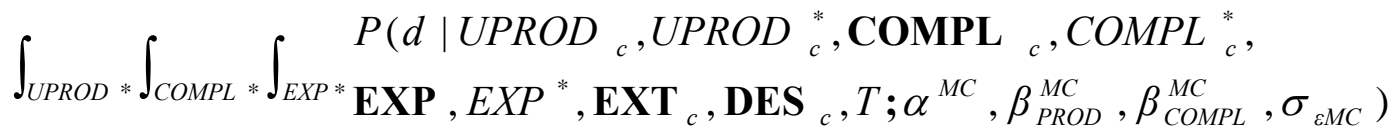

$$
\begin{aligned}
& f 1\left(U_{P R O D}^{*} \mid \mathbf{C O M P L}_{c}, \mathbf{E X P}, \mathbf{E X T}_{c}, \text { DES }_{c}, T ; \alpha^{P R O D}, \beta^{P R O D}, \beta_{\text {COMPL }}^{P R O D}, \beta_{\text {EXPCOMPL }}^{P R O D}\right. \text {, } \\
& \left.\beta_{E X P}^{P R O D}, \boldsymbol{\beta}_{\text {EXT }}^{\text {PROD }}, \boldsymbol{\beta}_{\text {EXPEXT }}^{\text {PROD }}, \boldsymbol{\beta}_{\text {DES }}^{\text {PROD }}, \beta_{T}^{P R O D}, \sigma_{\varepsilon P R O D}\right) \\
& f 2\left(\mathrm{COMPL}^{*} \mid \mathbf{E X P}, \mathbf{E X T}{ }_{c}, \mathbf{D E S}_{c}, T ; \alpha^{C O M P L}, \beta_{E X P}^{C O M P L}, \boldsymbol{\beta}_{\text {EXT }}^{\text {COMPL }}, \boldsymbol{\beta}_{\text {EXPEXT }}^{\text {COMPL }}, \boldsymbol{\beta}_{\text {DES }}^{\text {COMPL }}\right. \text {, } \\
& \beta_{T}^{\text {COMPL }}, \sigma_{\varepsilon \text { COMPL }} \text { ) } \\
& f 3\left(E X P^{*}\right) d U P R O D{ }^{*} d C O M P L^{*} d E X P{ }^{*}
\end{aligned}
$$


Note that the conditional distributions of the latent constructs are expressed as $f 1$ for $U P R O D^{*}, f 2$ for $C O M P L^{*}$ and $f 3$ for $E X P^{*} \cdot f 1$ and $f 2$ are defined by equations (4) and (5) and $f 3$ is the standard normal distribution.

Next, the measurement equations are integrated. The conditional distributions of the indicators given the values of the latent variables are expressed in equations (6), (7) and (8) and are included as $g 1, g 2$ and $g 3$ respectively. Then, the joint probability of the observable variables $d$, $U P R O D_{c}, \mathbf{C O M P L}_{c}$ and $\mathbf{E X P}$ is expressed as:

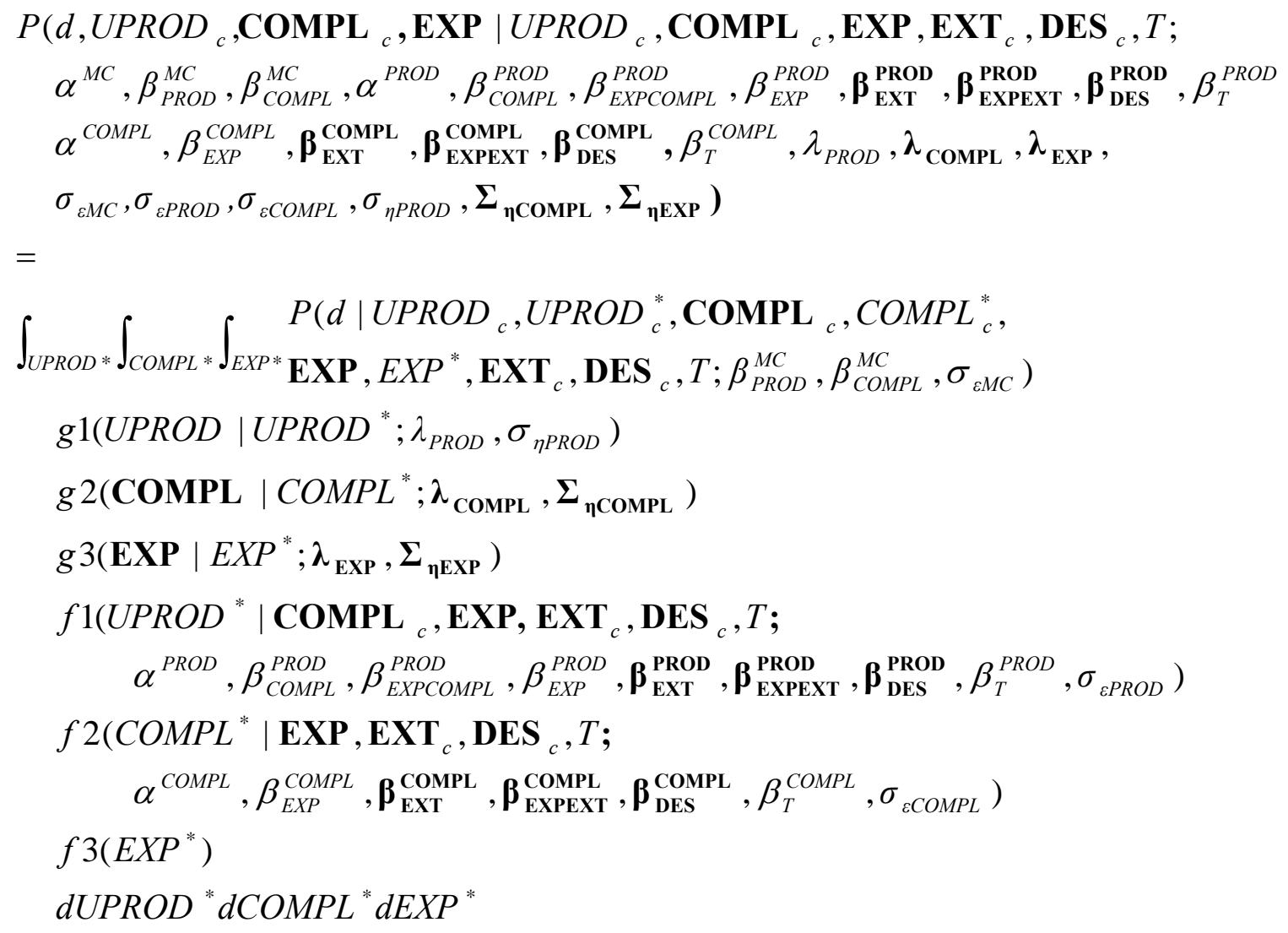

The total likelihood is then the product of the probabilities over all individuals and over all observations within individuals.

Estimation of the proposed model is done by means of a simulated maximum likelihood procedure that approximates the joint density of the distribution of the latent constructs and the 
individual-specific error components in the model. Simulated maximum likelihood procedures operate in the same way as maximum likelihood procedures, but use simulated probabilities instead of the exact probabilities. The simulated probabilities in our estimation procedure are based on draws from random components for each individual for the three latent constructs and for each random coefficient. In our application we have several observations for each individual, therefore the individual random component for each individual remains constant for all observations from the same individual within each round of simulation. The draws are based on a Halton sequence to give an even coverage over the distributions.

We then transform these draws with different parameters to estimate the differences in variance, both across the latent constructs and the random coefficients. The draws and the parameters jointly provide the value of the simulated likelihood, which is then maximized in its parameters instead of the true like likelihood. It has been shown that this procedure is asymptotically equivalent to regular maximum likelihood procedures (e.g., Train 2003). 


\section{References}

Alba, Joseph W. and J. Wesley Hutchinson (1987), “Dimensions of Consumer Expertise,” Journal of Consumer Research 13(March), 411-454.

Allenby, Greg M., Neeraj Arora and James L. Ginter (1999), “On the Heterogeneity of Demand,” Journal of Marketing Research 36(November), 384-389.

Ashok, Kalidas, William R. Dillon and Sophi Yuan (2002), "Extending Discrete Choice Models to Incorporate Attitudinal and Other Latent Variables,” Journal of Marketing Research 39(February), 31-46.

Ben-Akiva, Moshe, Daniel McFadden, Tommy Gärling, Dinesh Gopinath, Joan Walker, Denis Bolduc, Axel Börsch-Supan, Philippe Delquié, Oleg Larichiev, Taka Morikawa, Amalia Polydoropoulou and Vithala Rao, (1999), "Extended Framework for Modeling Choice Behavior,” Marketing Letters 10(3), 187-203

Bettman, James R., Eric J. Johnson and John W. Payne (1990), “A Componential Analysis of Cognitive Effort in Choice,” Organizational Behavior and Human Decision Processes 45(1), 111-140.

Broniarczyck, Susan M., Wayne D. Hoyer and Leigh McAlister (1998), “Consumers’ Perceptions of the Assortment Offered in a Grocery Category: The Impact of Item Reduction,” Journal of Marketing Research 35(May), 166-176.

Chatterjee, Subimal and Timothy B. Heath (1996), "Conflict and Loss Aversion in Multiattribute Choice: The Effects of Trade-Off Size and Reference Dependence on Decision Difficulty,” Organizational Behavior and Human Decision Processes 67(2), 144-155.

Dabholkar, Pratibha A. and Richard Bagozzi (2002), “An Attitudinal Model of Technology-Based Self Service: Moderating Effects of Consumer Traits and Situational Factors," Journal of the Academy of Marketing Science 30(3), 184-201.

Hajivassiliou, Vassilis A. and Paul A. Ruud (1994), "Classical Estimation Methods for LDV Models Using Simulation,” in Robert F. Engle and Daniel L. McFadden eds., Handbook of Econometrics, Amsterdam: North Holland, 2384-2438.

Heath, Timothy B., Gangseog Ryu, Subimal Chatterjee, Michael S. McCarthy, David L. Mothersbaugh, Sandra Milberg and Gary J. Gaeth (2000), “Asymmetric Competition in Choice and the Leveraging of Competitive Disadvantages," Journal of Consumer Research 27(December), 291-308.

Huber, Joel, Dick R. Wittink, John A. Fiedler and Richard Miller (1993), “The Effectiveness of Alternative Preference Elicitation Procedures in Predicting Choice,” Journal of Marketing Research 30(February), 105-114. 
Huffman, Cynthia and Barbara E. Kahn (1998), "Variety for Sale: Mass Customization or Mass Confusion,” Journal of Retailing 74(4), 491-514.

Johnson, Eric J. and John W. Payne (1985), “Effort and Accuracy in Choice,” Management Science 31(3), 395-414.

Liechty, John, Venkatram Ramaswamy and Steven H. Cohen (2001), “Choice Menus for Mass Customization: An Experimental Approach for Analyzing Customer Demand with an Application to a Web-Based Information Service,” Journal of Marketing Research 38(May), 183-196.

McFadden, Daniel (1986), “The Choice Theory Approach to Market Research,” Marketing Science 5(Fall), 275-298.

Netemeyer, Richard G. and William O. Bearden (1992), “A Comparative Analysis of Two Models of Behavioral Intention,” Journal of the Academy of Marketing Science 20(Winter), 49-59.

Newell, Allen and Herbert A. Simon (1972), Human Problem Solving, Englewood Cliffs, N.J.: Prentice-Hall.

Park, C. Whan, Sung Youl Jun and Deborah J. MacInnis (2000), "Choosing What I Want versus Rejecting What I Don't Want: An Application of Decision Framing to Product Option Choice Decisions,” Journal of Marketing Research 37(May), 187-203.

Pine, B. Joseph II, Bart Victor and Andrew C. Boyton (1993), "Making Mass Customization Work,” Harvard Business Review 71(5), 108-122.

Simonson, Itamar, Thomas Kramer and Maia Young (2003), "Effect Propensity: The Location of the Reference State in the Option Space as a Determinant of the Direction of Effects on Choice,” Research paper no. 1788, Graduate School of Business, Stanford University.

Slovic, Paul (1972), “From Shakespeare to Simon: Speculations and Some Evidence about Man's Ability to Process Information,” Oregon Research Institute Research Monograph 12(2).

Spence, Mark T. and Merrie Brucks (1997), “The Moderating Effect of Problem Characteristics on Experts’ and Novices’ Judgments,” Journal of Marketing Research 34(May), 233-247.

Train, Kenneth (2003), Discrete Choice Methods with Simulation, Cambridge, UK: Cambridge University Press.

Tversky, Amos and Daniel Kahneman (1991), "Loss Aversion in Riskless Choice: A ReferenceDependent Model,” Quarterly Journal of Economics 106(4), 1039-1062.

Wind, Jerry and Arvind Rangaswamy (2001), "Customerization: The Second Revolution in Mass Customization,” Journal of Interactive Marketing 15(1), 13-32.

Wright, Peter (1975), “Consumer Choice Strategies: Simplifying vs. Optimizing,” Journal of Marketing Research 12(February), 60-67. 